\title{
The Contribution of Non-Food-Based Exposure to Gluten on the Management of Coeliac Disease
}

\author{
Sophie W. Hall ${ }^{1,2}$, Ron Shaoul ${ }^{3(1)}$ and Andrew S. Day ${ }^{2, *(1)}$ \\ 1 Nutrition \& Dietetics, Christchurch Hospital, Christchurch 8140, New Zealand; sophie.hall@otago.ac.nz \\ 2 Department of Paediatrics, University of Otago Christchurch, Christchurch 8140, New Zealand \\ 3 Pediatric Gastroenterology \& Nutrition Institute, Ruth Children's Hospital of Haifa, Rambam Medical \\ Center, Faculty of Medicine, Technion, Haifa 3109601, Israel; ron.shaoul@gmail.com \\ * Correspondence: andrew.day@otago.ac.nz
}

Received: 29 April 2020; Accepted: 19 May 2020; Published: 22 May 2020

\begin{abstract}
The management of coeliac disease involves the life-long adherence to a strict gluten free diet. There have been concerns about exposure to gluten or other cereal components that are not contained in foods. This manuscript reviews the available literature focused on the potential for exposure to non-food-based gluten and the potential relevance of this to the ongoing management of individuals with coeliac disease. The products of consideration included dental and oral hygiene products, cosmetics and packaging products. Each of these items has been considered, with caution noted in regards to dental products and potential concern about novel packaging applications. Accidental ingestion by younger children of items such as play-dough during play also requires care. In conclusion, there is currently little firm data to guide individuals with coeliac disease, other than caution about specific items.
\end{abstract}

Keywords: coeliac disease; gluten; gluten-free diet; cosmetics; hydrolyzed wheat proteins

\section{Introduction}

Coeliac disease (CD) is an immune-mediated condition that occurs in around one percent of the population internationally, with certain population groups having increased susceptibility to developing CD [1]. It is triggered by gastrointestinal exposure to gluten in these susceptible individuals, causing varying degrees of villous damage. This resultant enteropathy can lead to a number of both gastrointestinal and extra-intestinal symptoms and the potential for longer term complications of untreated disease, such as nutrient deficiencies, poor growth in children, dental enamel defects, reduced fertility, fractures and some cancers [1-3].

The mainstay of treatment and management for $\mathrm{CD}$ is to avoid dietary gluten exposure through a strict, lifelong gluten free diet (GFD). Although concern about gluten exposure in the management of a GFD for CD is primarily focused on food-based exposure, gluten can also be present in a number of other non-products, such as plastics, dental equipment, pharmaceuticals and cosmetics [4-8]. As food-based exposure to gluten is the focus of most education for CD management, there is a potential for these other sources to be overlooked. Hence, contact with these non-food-based products has the potential to contribute to ongoing gluten inadvertent exposure and confound the rigour of a strict GFD.

This manuscript aimed at reviewing the limited literature available on the extent of exposure to gluten that non-food products could pose to patients with CD and the potential effect of these non-food sources of gluten on the effective management of CD. Relevant literature was identified from a Pubmed search (for publications up to April 1st, 2020) using cosmetics and gluten, cosmetics and coeliac, and 
dental equipment and coeliac as primary search terms. The reference lists of relevant publications were also reviewed.

\section{Oral Hygiene and Dental Products}

Non-food items designed to be used in the mouth such as dental equipment and oral hygiene products warrant consideration as to their potential contribution to gluten exposure due to their high risk of ingestion. It is known that even small amounts gluten ingested can cause ongoing symptoms [9].

One case report highlights the importance of considering gluten in dental prostheses (Table 1) [7]. This case report involved a nine-year-old girl who had ongoing symptoms and persistent elevation of tissue transglutaminase levels despite careful adherence to a GFD. It was subsequently realized that her orthodontic retainer contained gluten in the form of a plasticized methacrylate polymer. With removal of this retainer, the child had complete resolution of symptoms and full seroconversion.

Table 1. Possible non-food gluten sources which may impact patients with coeliac disease (CD).

\begin{tabular}{|c|c|c|}
\hline Reference & Type & Remarks \\
\hline Memon [7] & Dental prostheses & One case report \\
\hline Verma [8] & Toothpaste, lipstick & $\begin{array}{l}\text { Borderline amount in only } 4 \text { of } 62 \text { oral hygiene and care } \\
\text { products }\end{array}$ \\
\hline $\begin{array}{c}\text { Sharma [4] } \\
\text { Burnett [5] } \\
\text { Lauriere [10] } \\
\text { Pecquet [11] } \\
\text { Nakamura [12] } \\
\text { Tammaro [13] } \\
\text { Thompson [14] }\end{array}$ & Topical cosmetics & $\begin{array}{l}\text { Some contain gluten or hydrolyzed wheat proteins } \\
\text { (shown to illicit allergic reactions). The impact on people } \\
\text { with CD unclear }\end{array}$ \\
\hline El-Wakil [15] & $\begin{array}{l}\text { Wheat starch-based food } \\
\text { wrap }\end{array}$ & No data yet \\
\hline $\begin{array}{l}\text { Hlywaik [16] } \\
\text { Weisbrod [17] }\end{array}$ & $\begin{array}{l}\text { Play-dough, finger paint, } \\
\text { dry pasta }\end{array}$ & Possible exposure if swallowed \\
\hline
\end{tabular}

Gluten has become an increasingly used component in the materials used for this and related products, reflecting an increased demand for biodegradable yet sturdy materials. Although this is the only such case reported to date, this may be increasingly important, especially given the use of these dental products in children.

A recent report from an Italian group evaluated the gluten content of 66 oral hygiene and care products (toothpaste, dental tablets, mouthwashes, lipsticks and lip balms) available in Italian supermarkets and pharmacies (Table 1) [8]. These products are perhaps more relevant to an individual on a GFD as a portion may be more easily ingested. None of the products assessed contained ingredients derived from rye, barley or wheat: none of the products were labelled as gluten free. The gluten content of each of the products was ascertained by enzyme linked immunosorbent assay (ELISA). Only four of the products $(6 \%)$ were found to have a gluten content greater than 20 parts per million (ppm). The authors concluded that gluten contamination from these Italian products was unlikely to be an issue. They did, however, also conclude that gluten contamination could be relevant and that better labelling is required.

There have not been any equivalent studies conducted elsewhere. Although many products may be similar, a general caution may still be required.

\section{Cosmetics}

There is a broad range of cosmetics available on the market, including creams, moisturizers and powders applied topically as well as haircare products and sprays. Many of these products may contain 
gluten, especially hydrolyzed wheat proteins (HWP). One well-documented concern about exposure to these proteins has been contact reactions, including urticaria [10,11]. It appears that a number of different HWP, especially those of a larger size, can contribute to these local allergic reactions [12].

The relevance of these local reactions to individuals with CD is not completely clear. In general, unlike toothpastes and other oral hygiene products, topical cosmetics would not be expected to be ingested. Although it is clear that CD can manifest with dermatologic symptoms as a result of gluten ingestion, there is no reason to suspect that individuals with CD should be more likely to develop local reactions, such as urticaria, on topical exposure to gluten. Similarly, there is no data showing that repeated skin exposure to gluten containing products has relevance to the duodenal mucosa.

The impact of skin reactions in a group of 14 patients was evaluated in an Italian study [13]. All the subjects in this study developed topical dermatitis following the use of various cosmetic products. Skin lesions resolved completely following a change to products known and shown to be gluten-free, with no recurrence over the subsequent six months. This report did not, however, comment on gastrointestinal symptoms, serological changes or duodenal histology.

With regards to gastrointestinal exposure to non-food sources of gluten, although there is potential for consumption, it is thought unlikely that sufficient amounts of gluten could be ingested through use of gluten-containing non-food products such as lipsticks, hair-sprays and hand cream to elicit reactions $[5,8,14]$.

However, unlike the stringent regulations placed on food and drink products, it can be challenging to ascertain clear information on potential sources of gluten in cosmetic products $[4,18]$. Sharma and colleagues [4] measured the gluten levels in 36 cosmetic products by ELISA. No gluten was detected in any of the nine products labelled to be gluten free. However, wide variations in the gluten content of the various cosmetics was seen with gluten measured at up $1453.5 \mathrm{ppm}$ in six products. In five of the products shown to have detectable gluten, gluten or HWP were identified as ingredients. This study was mainly focused on analytical aspects and did not consider the relevance of the gluten content to individuals with coeliac disease.

\section{Other Products}

Advances in technology and demand for better food packaging products have led to numerous new products. The addition of wheat starch to paper increases the strength of the new product and also results in enhanced anti-bacterial activities (Table 1) [15]. The impact of such products has not been considered in the context of a GFD, but given that such products are designed for wrapping of food, this may become a potential issue in the future.

Finally, consideration also needs to be given to education surrounding non-food sources of gluten in the paediatric population such as play-dough and finger paint (Table 1). Both can be prepared using gluten-containing ingredients and have a high risk of consumption [16,17].

\section{Conclusions}

To date, literature surrounding the impact of non-food-based gluten exposure in CD is sparse. Strict labelling laws around the gluten content of food, drink and pharmaceuticals are not currently applied to non-food items, making it more challenging to ascertain clear information on the gluten content of different products. This leaves the potential for chronic low-level ingestion of gluten from non-food sources, particularly those related to oral care. The impact of topical exposure to gluten has also not been clearly elucidated in patients with CD.

Although gluten exposure from non-food sources is unlikely to be a major contributor to ongoing gluten exposure and symptoms in a majority of those with CD, it warrants consideration in cases of persistently active disease or symptoms.

Author Contributions: A.S.D. developed the design and concept. S.W.H. and A.S.D. reviewed the available literature and prepared the first draft of the manuscript. All authors contributed to the preparation of the manuscript. All authors have read and agreed to the published version of the manuscript. 
Conflicts of Interest: The authors declare no conflict of interest.

\section{References}

1. Lebwohl, B.; Sanders, D.S.; Green, P.H.R. Coeliac disease. Lancet 2018, 391, 70-81. [CrossRef]

2. Oxentenko, A.S.; Rubio-Tapia, A. Celiac Disease. Mayo Clin. Proc. 2019, 94, 2556-2571. [CrossRef] [PubMed]

3. Husby, S.; Koletzko, S.; Korponay-Szabó, I.; Kurppa, K.; Mearin, M.L.; Ribes-Koninckx, C.; Shamir, R.; Troncone, R.; Auricchio, R.; Castillejo, G.; et al. European Society Paediatric Gastroenterology, Hepatology and Nutrition Guidelines for Diagnosing Coeliac Disease. J. Pediatr. Gastroenterol. Nutr. 2020, 70, 141-156. [CrossRef] [PubMed]

4. Sharma, G.M.; Rallabhandi, P.; Williams, K.M.; Herrmann, M.; Sadrieh, N. Gluten Quantitation in Cosmetic Products by Enzyme-Linked Immunosorbent Assay. J. AOAC Int. 2016, 99, 586-590. [CrossRef] [PubMed]

5. Burnett, C.; Bergfeld, W.F.; Belsito, D.V.; Hill, R.A.; Klaassen, C.D.; Liebler, D.C.; Marks, J.G.; Shank, R.C.; Slaga, T.J.; Snyder, P.W.; et al. Safety Assessment of Hydrolyzed Wheat Protein and Hydrolyzed Wheat Gluten as Used in Cosmetics. Int. J. Toxicol. 2018, 37, 55S-66S. [CrossRef] [PubMed]

6. Mangione, R.A.; Patel, P.N. Caring for patients with celiac disease: The role of the pharmacist. J. Am. Pharm. Assoc. 2008, 48, e125-e139. [CrossRef] [PubMed]

7. Memon, Z.; Khan, A.; Hashmi, H.; Gelfond, D.; Baker, S.S. An Orthodontic Retainer Preventing Remission in Celiac Disease. Clin. Pediatr. 2013, 52, 1034-1037. [CrossRef] [PubMed]

8. Verma, A.K.; Lionetti, E.; Gatti, S.; Franceschini, E.; Catassi, G.N.; Catassi, C. Contribution of Oral Hygiene and Cosmetics on Contamination of Gluten-free Diet. J. Pediatr. Gastroenterol. Nutr. 2019, 68, 26-29. [CrossRef] [PubMed]

9. Hill, I.D.; Dirks, M.H.; Liptak, G.S.; Colletti, R.B.; Fasano, A.; Guandalini, S.; Hoffenberg, E.J.; Horvath, K.; Murray, J.A.; Pivor, M.; et al. Guideline for the Diagnosis and Treatment of Celiac Disease in Children: Recommendations of the North American Society for Pediatric Gastroenterology, Hepatology and Nutrition. J. Pediatr. Gastroenterol. Nutr. 2005, 40,1-19. [CrossRef] [PubMed]

10. Lauriére, M.; Pecquet, C.; Bouchez-Mahiout, I.; Snégaroff, J.; Bayrou, O.; Raison-Peyron, N.; Vigan, M. Hydrolysed wheat proteins present in cosmetics can induce immediate hypersensitivities. Contact Dermat. 2006, 54, 283-289. [CrossRef] [PubMed]

11. Pecquet, C.; Lauriére, M.; Huet, S.; Leynadier, F. Is the application of cosmetics containing protein-derived products safe? Contact Dermat. 2002, 46. [CrossRef] [PubMed]

12. Nakamura, M.; Yagami, A.; Hara, K.; Sano-Nagai, A.; Kobayashi, T.; Matsunaga, K. Evaluation of the cross-reactivity of antigens in Glupearl $19 S$ and other hydrolysed wheat proteins in cosmetics. Contact Dermat. 2016, 74, 346-352. [CrossRef] [PubMed]

13. Tammaro, A.; Narcisi, A.; De Marco, G.; Persechino, S. Cutaneous Hypersensitivity to Gluten. Dermatitis 2012, 23, 220-221. [CrossRef] [PubMed]

14. Thompson, T.; Grace, T. Gluten in Cosmetics: Is There a Reason for Concern? J. Acad. Nutr. Diet. 2012, 112, 1316-1323. [CrossRef]

15. El-Wakil, N.; Hassan, M.; Abou-Zeid, R.E.; Dufresne, A. Development of wheat gluten/nanocellulose/titanium dioxide nanocomposites for active food packaging. Carbohydr. Polym. 2015, 124, 337-346. [CrossRef]

16. Hlywaik, K.H. Hidden Sources of gluten. Prac. Gastrenterol. 2008, 32, 27-39.

17. Weisbrod, V.M.; Silvester, J.A.; Raber, C.; Suslovic, W.; Coburn, S.S.; Raber, B.; McMahon, J.; Damast, A.; Kramer, Z.; Kerzner, B. A Quantitative Assessment of Gluten Cross-contact in the School Environment for Children with Celiac Disease. J. Pediatr. Gastroenterol. Nutr. 2020, 70, 289-294. [CrossRef] [PubMed]

18. Prakash, P.; Jakhete, N.; Watts, K.; Derani, L.; Borum, M. Information About Cosmetic Ingredients Is Difficult to Obtain: A Potential Hazard for Celiac Patients. Am. J. Gastroenterol. 2011, 106, S93. [CrossRef]

(C) 2020 by the authors. Licensee MDPI, Basel, Switzerland. This article is an open access article distributed under the terms and conditions of the Creative Commons Attribution (CC BY) license (http://creativecommons.org/licenses/by/4.0/). 